\title{
Nature of eclogitic diamonds from Yakutian kimberlites: evidence from isotopic composition and sulphide inclusion chemistry
}

Bulanova, G.P. ${ }^{1}$, and Shelkov, D. ${ }^{2}$

1. TsNIGRI, 129B, Varshavsky shosse, Moscow, Russia.

2. Planetary Science Research Institute, The Open University, Milton Keynes, MK7 6AA, UK.

\section{Introduction.}

Previous workers have suggested alternative parageneses for diamondiferous eclogites, either originating from primary mantle melts (eg. Smyth et al., 1989) or from subduction and high pressure-temperature melting of crustal material (Helmstaedt and Doig, 1975). The paragenesis of diamonds with abundant sulphide inclusions has long been the subject of controversy. Meyer (1987) and Deines and Harris (1995) have suggested that many diamonds belong to a discrete sulphide paragenesis, unrelated to either the peridotitic or eclogitic parageneses generally advocated for the origin of diamonds with silicate inclusions. In this paper we present new data on Yakutian eclogitic diamonds which reveal their nature, origin, and genetic groupings.

\section{Samples and analytical methods.}

Twenty eclogitic diamonds from kimberlitic pipes Mir and 23d Party Congress (MaloBotuobinsky kimberlitic field) were studied, seven containing sulphides. Information obtained about syngenetic inclusions and diamonds has been linked to their growth history. Internal structure was examined by cathodoluminescence (CL) and birefringence imaging of central diamond plates, sawn and polished on the $\{110\}$ plane. For some diamonds hydrogen $(\mathrm{H})$ and nitrogen $(\mathrm{N})$ contents and aggregation state were identified by FTIR. The chemistry of inclusions was studied by electron microprobe, proton microprobe and ion microprobe (IMP) Carbon (C) and $\mathrm{N}$ isotopic composition was analysed by mass-spectrometry, mainly on fragments of diamond off-cuts, with some in-situ analyses on diamond plates. Sulpher (S) isotopic composition of sulphide inclusions was determined by IMP.

\section{Results and discussion}

Deines and Harris (1995) showed that for stones from many locations in Africa, sulphide inclusions with low $\mathrm{Ni}$ concentrations can occur in diamonds of low as well as high $\delta^{13} \mathrm{C}$ content. From the calculated lack of equilibrium of sulphides with mantle olivine these authors concluded also that a particular group of sulphide inclusions $(80 \%)$ with low $\mathrm{Ni} / \mathrm{Fe}$ ratio could not be ascribed to either peridotitic or eclogitic parageneses and should be recognised as a third "sulphide" paragenesis.

Using their and other published data plus our own results we are able to classify the sulphidebearing diamonds into peridotitic and eclogitic parageneses, each subdivided in turn into further genetic groups. Our identification of genetic groups of eclogitic diamonds was based on correlation of their internal structure, history of growth, presence of coesite inclusions, chemistry and $S$ isotopic composition of sulphide inclusions, and $\mathrm{C}$ and $\mathrm{N}$ isotopic composition of diamonds (Table 1).

Table 1. Quantitative characteristics of Sf-bearing eclogitic diamonds.

\begin{tabular}{|l|l|l|c|c|l|l|l|l|}
\hline \multicolumn{2}{|l|}{ Group } & Cs & $\begin{array}{c}\delta^{13} \mathrm{C} \\
\% o\end{array}$ & $\begin{array}{c}\delta^{15} \mathrm{~N} \\
\% o\end{array}$ & $\begin{array}{l}\delta^{34} \mathrm{~S} \text { of Sf } \\
\% o\end{array}$ & $\begin{array}{l}\text { Ni in Sf } \\
\text { wt \% }\end{array}$ & $\begin{array}{l}\text { Cu in Sf } \\
\text { wt \% }\end{array}$ & $\begin{array}{l}\text { Mo in Sf } \\
\text { ppm }\end{array}$ \\
\hline \multirow{2}{*}{1} & $\mathrm{a}$ & no & -16 to -12 & -1.3 to +3.5 & +2 to +4 & 0.7 to 3 & 0.7 to 1.4 & $<8$ to 66 \\
\cline { 2 - 8 } & b & no data & -20 to -12 & no data & -3 to +14 & 4.5 to 12 & 0.06 to 2 & no data \\
\hline 2 & a & no data & -9 to -2.8 & no data & -7 to +5 & 0.2 to 3 & 0.05 to 1 & no data \\
\cline { 2 - 8 } & b & yes & -7 to -4 & -2 to -0.2 & -1 to +2 & 3 to 12 & 3 to 4 & 60 to 300 \\
\hline
\end{tabular}

To date we have such data for only a small collection of diamonds, but we believe the use of such complete associated information is instructive and may be more meaningful than an abundance of stand-alone analyses, taking into account the complex history of growth of diamonds and the inhomogeneous composition of sulphides. The two main groups of eclogitic diamonds are called Light $\delta^{13} \mathrm{C}$ (group1) and Heavy $\delta^{13} \mathrm{C}$ (group 2). These groups were then further subdivided into Low-Ni (a) and High-Ni (b), according to the Ni content in sulphide inclusions (Table 1, Fig. 1). 


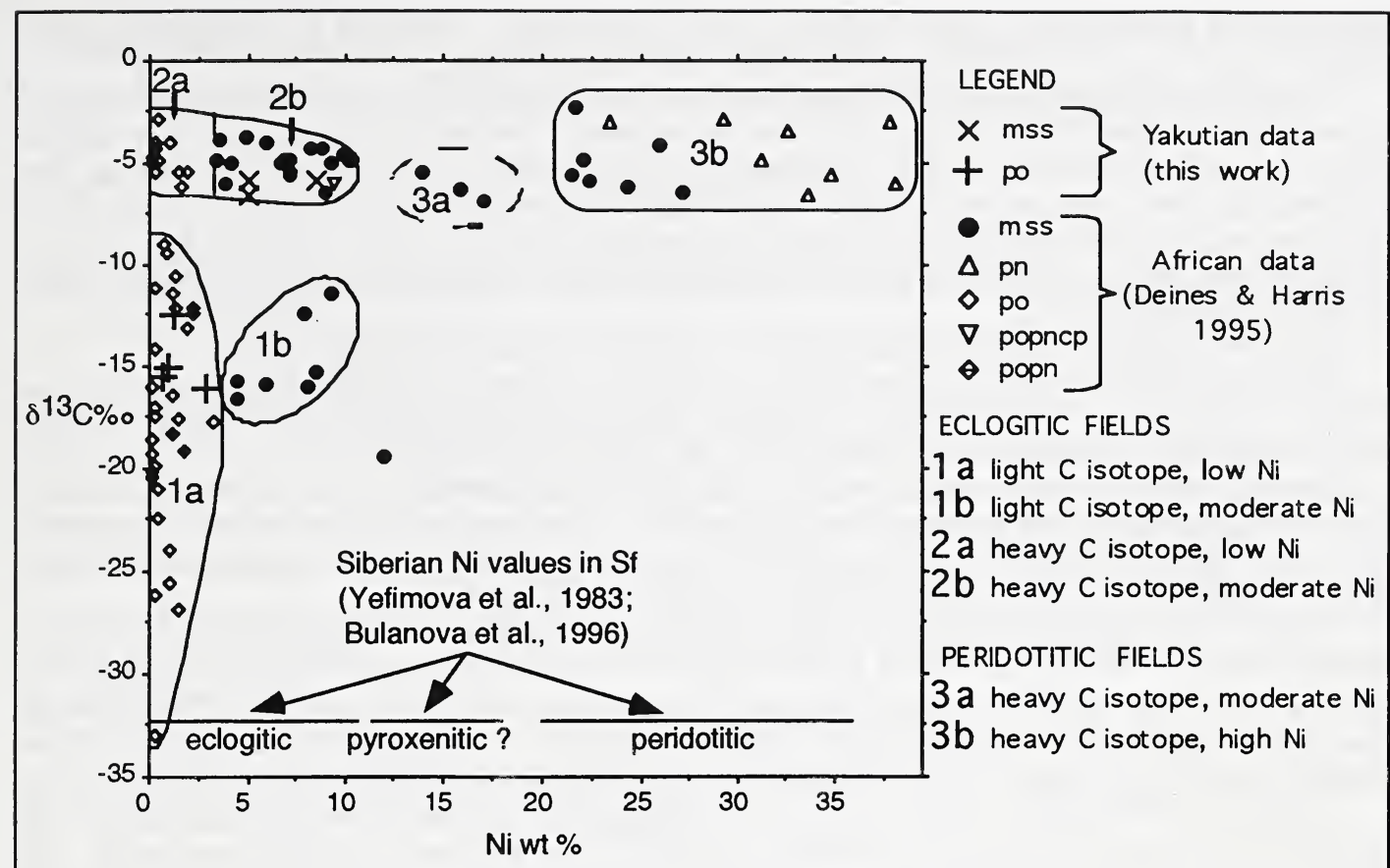

Fig. 1. Fields for eclogitic and peridotitic diamond parageneses, from $\delta^{13} \mathrm{C}$ and $\mathrm{Ni}$ content in sulphides

Light $\delta^{13} \mathrm{C}$, low Ni-Sf (Groupla) are represented by rough-layered octahedrons having simple octahedral zonation and one stage of growth. They have homogeneous blue CL colour and were grown by tangential mechanism of growth. The diamonds show low content of $\mathrm{N}$, very low $\mathrm{N}$ aggregation (type laA mainly) and no $\mathrm{H}$. The diamonds do not contain Cs inclusions, have light $\mathrm{C}$ isotopic composition and $\mathrm{N}$ isotopes ranging from negative to positive values (Table 1). Numerous $\mathrm{Sf}$ inclusions in the diamonds are represented by pyrrhotite with low contents of $\mathrm{Ni}, \mathrm{Cu}$ and $\mathrm{Mo}$, and positive $\mathrm{S}$ isotope values (Table1).

The majority of eclogitic diamonds and their sulphide inclusions analysed by Deines and Harris (28 from 37 with light carbon isotope composition) appear to belong to genetic Group 1a (Fig.1). The remaining nine are richer in $\mathrm{Ni}, 5-12 \mathrm{wt} \%$, and belong to Grouplb (Fig1). Other published data (Eldridge et al, 1991) also show predomination of the Groupla chemistry of sulphide inclusions for eclogitic African diamonds ( 21 from 26 ). Their $\delta^{34} \mathrm{~S}$ values lie in a wider range, from -10 to $+13 \%$, which is a characteristic feature of crustal sulphur, implying origin by subduction of crustal material, which is supported by the light carbon isotope composition obtained for Group 1 stones by other workers. Eldridge et al (1991) themselves did not analyse C isotopes for their diamonds.

Heavy $\delta{ }^{13} \mathrm{C}$, moderate Ni-Sf (Group 2b) are represented by thin layered and slightly stepped octahedrons, with complicated internal structure giving evidence of two or more stages of diamond formation. Their cores have cubic, rounded or more complex shape (intergrowths or aggregates). During late stages the growth shape changes to rough-layered and then to the thin layered octahedron. Core zones have yellow or yellow-green CL colour followed by blue CL colour for the octahedral zones. The change of CL colour and shape of growth correspond with fibrous, hummocky or mixed mechanism of growth for the seed zones and a layer by layer mechanism for the rim zones. FTIR spectroscopy shows a high or medium degree of $\mathrm{N}$ aggregation and presence of $\mathrm{H}$ in the central rounded zones, and a low content and degree of aggregation of $\mathrm{N}$ in the rim zones. Inclusions of $\mathrm{Cs}$ and $\mathrm{K}-\mathrm{Al}-\mathrm{Si}$-phase (partly crystallised melt?) are a characteristic feature of the diamonds, providing evidence of the presence of melt (fluid) during their growth. C isotopic composition of the stones lies within the field of isotopically heavy peridotitic and eclogitic diamonds (Table1, Fig.1). N isotopic composition of the diamonds shows negative values. Sulphide inclusions in the diamonds are 
represented by monosulphide solid solution (Mss) with moderate content of $\mathrm{Ni}, \mathrm{Cu}$ and $\mathrm{Mo}$, and $\mathrm{S}$ isotopic composition within the range from +2 to $-1 \delta^{34} \mathrm{~S} \%$ (Table1).

The majority of sulphide inclusions from isotopically heavy eclogitic African diamonds analysed by Deines and Harris (1995) (18 from 30) show Ni contents in sulphides comparable to our eclogitic Group $2 b$ (Fig1). Nevertheless eleven of them are low Ni sulphides, which we call Group $2 a$. Five sulphide inclusions from data of Eldridge et al. (1993) might also belong to group $2 \mathrm{~b}$, because of a similar range of Ni content ( $3-9 \mathrm{wt}$. \%) and the narrow range of $\delta^{34} \mathrm{~S}$ (from -1 till $+3 \%$ ). These S isotope values and the heavy $\mathrm{C}$ isotopic composition of the diamonds suggest a mantle source, without crustal input.

Fig 1 also shows peridotitic diamond data for comparison with the eclogitic results.

Field $3 \mathrm{~b}$ corresponds to high Ni peridotitic sulphide inclusions (22-36.6\% Ni), (Bulanova et al, 1996). Field $3 a$ represents peridotitic sulphide inclusions with medium (12-19\%) Ni content, probably belonging to the pyroxenite paragenesis (Bulanova et al, 1996).

The fields shown are in a good agreement with all previous data about $\mathrm{C}$ isotope composition of the two main parageneses of diamonds from kimberlites. Thus, peridotitic diamonds are isotopically heavy, and contain high-Ni sulphide inclusions having a restricted sulphur isotopic composition. There is no doubt about their mantle origin and source of $\mathrm{C}, \mathrm{N}$ and $\mathrm{S}$.

Eclogitic diamonds lie within the two fields of composition. Isotopically heavy eclogitic diamonds (field 2) should also have a mantle origin. The majority of sulphide inclusions in these diamonds have high content of $\mathrm{Ni}$ and restricted composition of $\delta^{34} \mathrm{~S}$, (Group 2b). They probably represent a paragenesis of coesite eclogites of magmatic origin. Isotopically heavy diamonds with low Ni sulphide inclusions (Group 2a) might belong to other varieties of mantle eclogites.

A mantle metamorphic process with an input of crustal material more likely formed the isotopically light diamonds (field1) which have a wide $\delta^{34} \mathrm{~S}$ composition of sulphide inclusions. The minority of them might belong to the paragenesis of coesite eclogites (Group1b), but most of them represent other varieties of diamondiferous eclogites (Groupla).

\section{Conclusions}

There is a correlation of isotopic composition of diamonds with chemistry and S isotopic composition of associated sulphides. The data for Yakutian and African diamonds lie within similar compositional fields, implying similar diamond formation processes.

Sulphide inclusions in diamonds from kimberlites belong to the peridotitic or eclogitic paragenesis; there is no separate third sulphide paragenesis of diamonds.

Eclogitic diamonds in kimberlites can arise from subducted crustal material subjected to metamorphic events within the upper mantle (Group 1), or directly by igneous processes within the mantle (Group 2).

\section{Acknowledgements}

Research was carried out with the RFFI grant no. 96.05.65031. University College London, Open University (Milton Keynes), and YIGS are thanked for making facilities available for the work.

\section{References}

Bulanova, G.P., Griffin, W.L., Ryan, C.G., Shestakova, O.Ye., and Barnes, S.J., 1996, Trace elements in sulfide inclusions from Yakutian diamonds: Contrib. Mineral. Petrol. 124, p. 111-125.

Deines, \& Harris, 1995, Sulfide inclusion chemistry and carbon isotopes of African diamonds: Geochim. Cosmochim. Acta, Vol. 59, No. 15, p. 3173-3188.

Eldridge, C.S., Compston, W., Williams, I.S., Harris, J.W., and Bristow, J.W., 1991, Isotope evidence for the involvement of recycled sediments in diamond formation: Nature 353, p. 649-653.

Helmstaedt, H, and Doig, R., 1975, Eclogite nodules from kimberlite pipes of the Colorado Plateau samples of subducted Franciscan-type oceanic lithosphere; Phys. Chem. Earth 9, p. 95-111.

Meyer, H.O.A., 1987. Inclusions in diamond, In: Mantle Xenoliths (Ed. Nixon, P.H.), pp. 501222, Wiley.

Smyth, J.R., Caporuscio, F.A., and McCormick, T.C., 1989, Mantle eclogites: evidence of igneous fractionation in the mantle; Earth Planet. Sci. Lett. 93, p. 133-141.

Yefimova, E.S., Sobolev, N.V., and Pospelova, L.N., 1983, Sulphide inclusions in diamond and specific features of their paragenesis; Zap. Vsesoy. Mineral. Obsh. 112, p. 300-310 (in Russian). 